\title{
Understanding middle managers' influence in implementing patient safety culture
}

\author{
Jennifer Gutberg ${ }^{*}$ (iD and Whitney Berta
}

\begin{abstract}
Background: The past fifteen years have been marked by large-scale change efforts undertaken by healthcare organizations to improve patient safety and patient-centered care. Despite substantial investment of effort and resources, many of these large-scale or "radical change" initiatives, like those in other industries, have enjoyed limited success - with practice and behavioural changes neither fully adopted nor ultimately sustained - which has in large part been ascribed to inadequate implementation efforts. Culture change to "patient safety culture" (PSC) is among these radical change initiatives, where results to date have been mixed at best.

Discussion: This paper responds to calls for research that focus on explicating factors that affect efforts to implement radical change in healthcare contexts, and focuses on PSC as the radical change implementation. Specifically, this paper offers a novel conceptual model based on Organizational Learning Theory to explain the ability of middle managers in healthcare organizations to influence patient safety culture change.

Summary: We propose that middle managers can capitalize on their unique position between upper and lower levels in the organization and engage in 'ambidextrous' learning that is critical to implementing and sustaining radical change. This organizational learning perspective offers an innovative way of framing the mid-level managers' role, through both explorative and exploitative activities, which further considers the necessary organizational context in which they operate.
\end{abstract}

\section{Background}

Leadership is one of the most seemingly impactful and frequently cited factors associated with large-scale, 'radical' organizational change $[1,2]$. The attention given to leadership in implementation and change management research suggests that it plays a vital role in affecting significant reforms in organizations, notably in organizational culture change efforts [3-11]. Theories of both implementation and change management further support the purported importance of leadership at all levels facilitating such radical change, in particular leadership at the level of middle management - those with supervisory or managerial roles that are neither front-line workers nor senior leadership team members $[12,13]$. A recent body of evidence in healthcare suggests that engagement of leadership at multiple levels

\footnotetext{
* Correspondence: jennifer.gutberg@mail.utoronto.ca

Institute of Health Policy, Management and Evaluation, Dalla Lana School of Public Health, University of Toronto, 155 College Street, Toronto, ON M5T 3M6, Canada
}

of an organization is critical in affecting the success of strategic initiatives aimed at large-scale change, and in sustaining these changes long-term [14].

In spite of the increasing knowledge around the value of middle management both within and beyond the healthcare sector, our understanding of middle managers' contributions to strategy and organizational change remains limited [12, 13, 15, 16], despite numerous calls in the popular/lay literature to engage middle managers as a vital mechanism for effecting strategic change [17]. The need for senior leadership and a strong vision in creating change has been well established, yet the persistent challenge of sustaining large-scale change initiatives [18-20] does underscore the importance of considering whether senior leadership may be a "necessary but insufficient" condition to enact meaningful sustained change. Further, given the increased focus in healthcare on team- and clinical microsystem-level functioning, leadership is becoming even more diffuse across the organization [21] and by necessity middle management will play an increasingly significant role in improving organizations. 
In the context of healthcare organizations, middle managers often have to work within highly hierarchical structures that are generally siloed by professional group (e.g., doctors, nurses, allied health professionals). In addition to having to balance the sometimes competing interests of these groups - and in fact often themselves being members of specialized professional groups, whose chief roles relate to patient care and not the conduct of strategic activities [22] - middle managers also face unique contextual constraints. That is, though middle managers have been described as having a 'semi-autonomous' role [23], in healthcare in particular middle managers are beholden to their profession, their patients, and senior management - exemplifying a phenomenon described by some organization scientists as "stuck in the middle" [24].

These contrasting views regarding middle managers' potential strategic value to organizations, against the unique contextual challenges they face, beg the question: how can middle managers in healthcare organizations influence organizational change, and under what circumstances will they be most effective in affecting this change?

In order to address this question in a practical and relevant context, this paper presents the issue of organizational change relating specifically to patient safety, focusing on discussion of middle managers roles in the implementation of strategies aimed at creating and improving patient safety culture. This focus, we think, is timely: as explained by Benn et al., "there is now growing recognition that patient safety and the capacity of an organisation to deliver consistent, highquality and failure-free care is both a systemic issue and one that needs to be addressed at the level of the whole organisation or care system" [25] (p.1767).

The paper will begin by framing the context of patient safety efforts and extant literature that reviews these efforts, followed by a review of the relevant evidence on middle management's involvement in change initiatives in healthcare. Together, these background elements will be used to justify the proposition of a theoretical framework for middle managers' contributions to organizational change, predicated on Organizational Learning Theory [26]. Organizational learning theory has been widely used across multiple sectors to explore large-scale change [26, 27], and emphasizes the need for organizations to explore both radical/whole system, and incremental, change innovations $[26,28,29]$.

\section{What we know about patient safety change initiatives}

In 1999, the Institute of Medicine released its seminal publication on patient safety and adverse events along with subsequent reports on healthcare quality [30-32].
Since those reports first emerged, these issues have become top of mind for almost every healthcare organization, including acute care facilities. The reports and others like them that followed [33] focused on elements for total redesign or 'radical change' of the system that put patient safety at the forefront of healthcare, and advocated changing from a culture of blame and fear to one of accountability, safety, and patient-centeredness [30]. As a result, patient safety has become ubiquitous and with it the effort to build patient safety cultures (PSC) $[31,34,35]$.

Despite over 15 years of progress, significant issues still exist with the conceptualization and execution of PSC initiatives and translating these to front-line outcomes. While there have been numerous successful efforts to change organizations' cultures, the current view remains that these efforts are often not fully sustainable and changes are not being adopted effectively $[36,37]$. In fact, some reports have found that while patient safety awareness has increased, implementation effectiveness and patient and organizational performance outcomes have actually worsened in areas $[18,38]$. It is clear that effecting PSC change is a challenging undertaking, and that our understanding of the factors that affect efforts to adopt PSC is limited.

The challenges in both measuring and improving organizational culture (and in turn PSC) are well documented within and beyond the healthcare literature $[39,40]$. The fundamental challenge results first from methodological difficulty in operationalizing organizational culture [41], as well as empirically validating a cause-andeffect relationship [25, 42]. Mearns and Flin suggest that safety culture in particular has its own set of methodological challenges, where efforts to assess a "safety culture" are often met with measurement of safety attitudes, with little attention paid to the norms, values, and rules that in fact embody a culture [41].

Though these perspectives are critical in any empirical or theoretical examination of organizational culture, a body of evidence does exist to support a) empirical efforts to improve organizational culture generally and patient safety culture specifically, and b) targeted strategic efforts aimed at improving culture [40, 43]. In particular, this has been manifested in much of the existing literature as concrete strategies such as unit-level programs, team-based interventions [44, 45], and broader organizational interventions (which could include single or multi-component interventions [40]) [43]. Though as mentioned above, the success of these initiatives is variable at best, this paper suggests that this is a result of implementation challenges - and specifically the relative absence of consideration of middle managers in effecting culture change - rather than a reflection of the interventions themselves. In light of this, the following section will 
offer an overview of the evidence around middle management's potential and realized contribution to organizational change, culture change, and strategy implementation.

Leadership's significance to broader organizational change in healthcare has previously been discussed herein. However, this link between leadership and patient safety culture change efforts in particular has also been examined. One systematic review found that leadership, in the form of executive walkrounds, was one of the strategies used to improve patient safety culture, though the evidence only found partial support for change in PSC climate [40]. Weaver et al. conducted another systematic review with similar aims, which found similar evidence for the effectiveness of leadership interventions - again in the form of executive walkrounds in the improvement of perceptions of safety culture, as well as patient outcomes [43]. It appears that interventions to improve patient safety culture focused on leadership seem to focus on the executive level. However, the potential value of non-senior leaders in influencing patient safety culture has also been considered: Kaplan et al. explain leadership drives patient safety culture, but add that "...one must look beyond the CEO and consider the roles of the entire executive team, the trustees or directors, and the leaders who are charged with managing teams in the organization. Strong leadership is also shared leadership..." In order to explore how these nonsenior leaders (in particular middle management) may contribute to patient safety culture change efforts, we review the extant literature on middle management's role in change in healthcare.

\section{Middle management's role in change initiatives in healthcare}

In order to understand middle management's potential contribution to patient safety culture efforts, the population being explored must first be defined. There is a significant gap in the literature regarding the identification of middle managers, which is explained through the following quote by McConville:

"Middle managers are more difficult to distinguish, as the boundaries between levels of hierarchy are often blurred. The exercise is further complicated in organisations with organic structures where demarcation may be ambiguous. As a result few writers have attempted to define the role. Middle line management is often described in terms of what it is not" [46] (p.639).

Indeed, a review of the literature finds that studies of "middle managers" in healthcare include undefined middle managers [47-51]; nurse managers [52-54]; 'unit-level' managers [55-57]; ward managers [23]; department leads [58]; clinical directors [59, 60]; facility manager [61]; as well as idiosyncratically-defined middle managers (i.e., where the authors intentionally set bounded criteria, possibly guided by the organization(s) in question being studies $[16,46])$. Though each level of management described above has a bounded set of responsibilities and may be more or less involved in regular strategic activities of the organization, the literature linking middle managers to organizational change does not appear to set limits on which middle managers would be able to contribute to organizational culture change. As a result, we consider "middle managers" herein as any individual in an organization who operates above the front-line of the organization, but below the level of senior management.

The potential value for middle managers to contribute to strategic organizational activities in healthcare is a relatively recent consideration, in comparison to the substantial existing literature emphasizing the importance of senior leadership [62]. Nevertheless, a growing body of evidence shows that middle management's position in the organization centres their contribution, particularly their ability to facilitate communication throughout the organization [63, 64].

The communication 'role' has been posited as an area where the middle manager influences change in organizations. An important example of this would be the work of Birken et al., who highlight the significance of middle managers in implementing evidence-based innovations [63, 65]. Though Birken's model also considers non-communication aspects (such as mediating between strategy and operational activities for employees), the model centres on the importance of diffusing, synthesizing, and 'selling' information related to innovation implementation $[63,65]$.

Additional literature finds that middle managers leverage their access to knowledge and networks to serve as a 'conduit', transferring information regarding the strategy down through the lower levels of the organization [63], while simultaneously translating the strategy or vision into actionable processes and steps to adopt by frontline employees [66-68]. Middle managers are also able to direct the flow of information both upward and downward (per Floyd \& Wooldridge's model [68], discussed further below), communicating from the front lines back up to senior leadership.

\section{Toward a conceptual/theoretical understanding of middle management's role in change initiatives in healthcare}

Kotter's model of change [69] presents a useful framework for understanding how middle management can leverage their position in a changing environment. Though middle managers can play an important role in almost every step of the model, communication is specifically cited in the first step, in creating a sense of urgency in the organization. In an analysis of Kotter's 
model, Appelbaum et al. elaborate on the communication paradigm by explaining that, among other factors, frequency of communication about the change in the organization is required to increase urgency about the change [70]. This again aligns with the evidence supporting the middle manager's role as the 'conduit' between senior management and front line employees in the organization. If the middle manager has proper knowledge, abilities, and resources from senior management, they will be able to generate the necessary frequency of communication regarding the upcoming change. The 4th stage of Kotter's model also references communication, whereby management must communicate the change vision to reduce uncertainty - or as stated by Appelbaum et al. [70] "tell people, in every possible way and at every opportunity, about the why, what and how of the changes" (p.766). The middle management role is again indirectly emphasized, highlighting that two-way communication is far more effective than one-way, honing in on a strength of this specific level of management [69].

In order for middle managers to successfully leverage these knowledge and communication skills, they must both understand their role and possess the requisite ability to leverage their position in the organization [71]. This is emphasized through the middle managers' understanding of the role itself, via role conflict and ambiguity [72]. 'Role theory', then, suggests that understanding of their role is a determinant of middle managers' ability to effectively implement strategy within their organization. This theory is based on the works of Floyd \& Wooldridge $[12,73,74]$ who presented a seminal framework of middle management roles. In brief, this model outlines the bidirectional role of middle management in strategy implementation, whereby they can influence upward (senior leadership) or downward (immediate or indirect subordinates) and through different communication strategies [68].

Although this framework is useful in understanding the inherent ambiguity of the middle manager's role as well as the potential ways to leverage this role, it does not explain how or why middle managers choose to leverage their influence (i.e., whether they enact more convergent or divergent communication strategies). Another theory that may be useful to explicate this phenomenon is social capital theory [75-77]. Very broadly, organizational social capital "consists of the structural (connections among actors), relational (trust between actors), and cognitive (shared goals and values among actors) dimensions of the relationships between organizational members" [78] (P.584, emphasis from authors). These structural, relational, and cognitive factors directly impact middle managers' ability to strategically manoeuvre within the organization, where structures either facilitate or hinder the middle manager's positioning
[79]. Embedded within the social capital theory is the concept of social networks [80], which emphasizes the strength of connections within and between organizations. Depending on the strength and breadth (both vertically and laterally) of the middle manager's network within the organization, their ability to access knowledge and communicate (or transfer) it effectively may be facilitated or constrained. Through social capital theory, it may be understood that middle managers are more or less effective based on the strength of their social networks and their organizational social capital. However, it could also be suggested that the strength of each network may influence which elements of the typology are adopted by the middle manager (e.g., based on their perceived ability to influence upwards or downwards more effectively).

Although social capital theory presents an important framework for considering the individual role and potential efficacy of middle managers, it is not sufficient in providing a macro- or organization-level view of middle managers' in facilitating radical change.

As is evident from our discussion above, much of the literature on middle management's contribution to organizational change emphasizes its position in the organization. Indeed, all of the aforementioned skills and capabilities required of middle managers to influence change leverage their position as intermediaries with access to knowledge and insights from both the executive and front-line levels of the organization. In light of this, we propose a theoretical framework exploring middle management's contribution to organizational culture change that not only examines this group's skills and capabilities, but also 'situates' these capabilities in the wider context of the organization, thus offering a means to understand when and how middle managers will operate most effectively. We suggest that organizational learning theory and the 'exploration versus exploitation' paradigm offers a meaningful avenue to explain this context, particularly within the frame of patient safety.

\section{Organizational learning theory as a framework for middle management}

Organizational learning theory is uniquely suited to address the various contextual factors associated with the middle manager's role [26]. Organizational learning theory is a meta-theory that considers the context in which learning about new knowledge takes place, and describes learning as the outcome of social processes. It suggests that individual-level factors, macro-environmental factors, and the nature of the knowledge itself influence how learners perceive action-outcome (cause-effect) relationships [81-83]. Organizational learning theory is highly relevant to understanding knowledge translation phenomena [84-89]. Some learning can be observed as changes in 
worker behaviours and work processes, while other learning cannot be observed since it leads to decisions to maintain the status quo. Learning about new knowledge that in turn begets new knowledge - in organizations can endure well beyond the tenure of individual workers who contribute to it: it can be embedded in formal policies and procedures, role descriptions, and information systems [82, 90, 91]. It can also be captured in less explicit forms including informal communication channels, culture, and behavioural norms $[85,92]$.

Organizational learning has garnered a great deal of research attention since it is related to organizational performance [81, 93]. Performance improvements in organizations are realized with accrued experience and enables organizations to knowingly learn and adapt their work routines [94]. This ability to "adaptively learn" is observed in health care settings [95]. Adaptive learning can accrue over time with no overt effort, or it can be intentional. Some organizations intentionally acquire new knowledge (e.g., evidence-based practice guidelines) from outside and create leaning opportunities (e.g., in the form of a pilot test) with the expectation that the ensuing learning will be adaptive - or beneficial to the organization. The performance variation that exists in every industry $[82,96]$ is suggested to be attributable, at least in part, to differences in organizations' capacity to learn [82], related to how they learn [97] and the resources that they make available for learning.

\section{Exploration vs. exploitation}

In organizational learning theory, organizations can be 'exploration' focused, 'exploitation' focused, or 'ambidextrous' where they create some combination of both strategies. Exploration refers to organizations' activities of searching, innovating, and risk-taking, while exploitation refers to efficiency, selection, and implementation [26]. Each of these in turn affects the organizational structures that the firm selects and develops, as a result of the overarching learning strategy it chooses to pursue, with the end goal of creating a competitive advantage based on their chosen lens.

Since its inception, this exploration/exploitation paradigm has been associated with an implicit dichotomy: how can an organization avoid the trade-offs of too much of either exploration or exploitation? Organizations that focus solely on exploration at the expense of exploitation are "likely to find that they suffer the costs of experimentation without gaining many of its benefits. They exhibit too many undeveloped new ideas... Conversely, systems that engage in exploitation to the exclusion of exploration are likely to find themselves trapped in suboptimal stable equilibria" [26] (P.71). This inherent dichotomy or structural tension is intuitively reminiscent of the tension observed in healthcare organizations and in the health services literature $[98,99]$, whereby leaders and providers are admonished to innovate while at the same time sustaining an acceptable level of patient safety. To emphasize this idea, one study presented a proposed model of the structures and ideologies that would encompass either an exploration- or exploitationbased organization [100]. In essence, this model demonstrates how significantly an organization is impacted by adopting an exploration or exploitation focus - from levels of hierarchy and centralization in the organization through modes of communication, even impacting at the micro level of group processes, determining whether groups will be goal-oriented (exploitation) or adaptable (exploration) [100].

In an attempt to address this issue, numerous authors have presented varying models of the 'ambidextrous organization', which successfully incorporates elements of both exploration and exploitation [29, 101, 102]. Though many iterations exist of how both elements would function in a singular organization, the dominant paradigm is that of Benner \& Tushman [29], whereby both elements can exist within sub-units of the organization, generally with very limited integration between these subunits and the larger organizational type [103].

\section{Middle managers as ambidextrous actors in organizations}

In terms of organizational change, exploration has been associated with 'radical' innovation, while exploitation has been linked only to incremental change [103]. In this vein, Posen and Levinthal [104] presented a model of exploration and exploitation specific to dynamic environments or turbulent environmental change. Though the model is highly comprehensive and a full overview is beyond this paper, the important focus is that change is a moving target, rather than an end goal [104]. This notion ties directly into efforts at changing patient safety cultures: initial change efforts may require allencompassing initiatives, however these efforts will never officially 'end', in that healthcare organizations will always have to uphold their standard of patient safety, facilitated by a strong PSC. In light of this, organizations need to adopt strategies that allow them to 'chase the moving target' without dedicating all of their resources to repeated change and quality improvement initiatives. This paper proposes that the adoption of a successful ambidextrous organizational structure - in particular for a healthcare organization - is best accomplished not through division of units, rather through division of 'levels' in the organization, capitalizing on the importance of middle management. Since middle managers are uniquely able to acquire and communicate knowledge across the organization, they are able to impact both strategic and operational outcomes. 
Based on the theory of organizational learning and the concept of exploration vs. exploitation, a series of propositions are presented as they relate to the middle manager's role in creating an ambidextrous healthcare organization to implement radical organizational change. The mechanics of this role are explained by the following propositions, whereby mid-level managers are situated between senior leadership that is strategy- or exploration-focused, and front-line workers that are operations- or exploitation-focused.

\section{Propositions}

As mentioned above, the Institute of Medicine's reports were fundamental in changing the nature of acute healthcare organizations as well as their basic understanding of what constitutes proper, patient-focused and safe care [30,31]. It could be posited that since then, acute healthcare organizations have adopted a perpetual exploration focus in their efforts at improvement and have become stuck in a cycle of 'perpetual pilots' [105]; the explosion of quality improvement initiatives and programs aimed at fostering patient safety and patientcentered care support the assumption that organizations have shifted their strategies to reflect these new goals. It could further be proposed that the end result of this focus has become exactly as originally predicted: organizations are suffering the costs of exploration (unfinished, unsustained, and costly ideas [106-108]) without reaping the benefits of long-term change. Furthermore, Posen and Levinthal emphasized the diminishing returns of constantly remaining in a state of exploration, where only so many changes can take place in an organization within a relatively short timespan [104]. This context for acute care organizations further emphasizes the expectation for senior leadership to be entirely explorationfocused when undergoing radical organizational change. Additionally, if the existing climate in healthcare is focused on innovation (notably in terms of technological innovation), it follows that policies and funding would support this structural change. As a result, senior leadership would be expected to dedicate all resources towards the focus on explorative organizational activities. Therefore, the first proposition is:

Proposition 1: Senior leadership in acute healthcare organizations engage primarily in exploration in their strategic activities

Given this organizational context, this then allows middle managers to adopt a different strategic focus than the remainder of the organization. Middle managers are not required to be as focused on vision and strategic planning as senior leaders, but still have the knowledge and context to focus on strategic priorities more so than would front-line employees. Given that their role most often involves bringing high-level ideas into actionable tasks for employees, middle managers may very well have a different focus than the rest of the organization when it comes to influencing organizational change. That is, middle managers serve an important role in balancing out the exploration vs. exploitation dynamic in a changing organization. As senior management is constantly focusing on vision, strategic planning, or any number of new changes occurring in the health system, it is the middle managers who a) translate the vision and strategy into action, and b) juggle the balancing act between the innovation focus of senior leadership and the operational efficiency required to function in a day-to-day environment. These roles assure that middle managers themselves adopt an ambidextrous view of the organization, engaging in both the explorative activities of senior leadership and the exploitative patient-facing activities of front-line workers. Not only does this leverage the skill and position of middle management, but it also assures that senior leadership is able to focus on developing truly radical notions of change in PSC, that are based on the reality of on-the-ground experiences of front-line workers.

\section{Proposition 2: Healthcare organizations will create stronger patient safety cultures when middle management adopts an ambidextrous view of change and innovation strategic activities}

Elaborating on the above proposition, there are two issues to consider: first, per this theoretical framework, there needs to be a different focus at each 'level' of the organization in order to function optimally and assure that both sides of the change management paradigm (radical vs. incremental change) are being considered. Second, if senior management specifically isn't focused on exploration, it will be near impossible for middle management to adopt change or innovation, particularly with no high-level representative to champion the change; the only exception to this might be if the middle managers were part of specific sub-units tasked with radical change, per Benner and Tushman's proposition [103].

Proposition 2a: Proposition 2 will only hold true when senior leadership is focused on exploration

As mentioned earlier, part of the proposition of the ambidextrous healthcare organization is not only that senior leadership is exploration-focused, but also that front-line workers are exploitation-focused. This delineation between exploration-focused senior leadership and exploitation-focused front-line workers is uniquely critical in the healthcare field, as organizations can be seen as struggling to achieve a balance between the need for 
radical innovation and equally resounding calls to improve patient safety. When considering these competing priorities from the perspective of the front-line worker, sustaining patient safety efforts requires an emphasis on implementing best practices and clinical guidelines, which leaves little time to focus on activities aimed at influencing organizational change (as demonstrated by quality improvement literature, which identifies lack of time as a barrier to front-line staff implementing quality improvement activities [109]). Given the nature of healthcare providers' already over-burdened schedules and difficulty keeping updated on the influx of such clinical guidelines [110], this only further hinders the possibility of embedding innovations and exploration-seeking activities into their practices.

Proposition 3: Front-line healthcare workers will generally adopt an exploitation-focus in performing their day-to-day and patient-facing activities

The different focus at each level of the organization, we suggest, creates a dynamic 'tension' in the organization (based on the organization's fundamental activities and structures) that - similar to the flow of communication exists in a bidirectional relationship. That is, when each level is focused on a different goal, a continuous feedback loop between the two can only reinforce the change process, which is ultimately the proposed role of the middle manager. Using the example of PSC, if middle management is able to effectively implement processes that improve patient outcomes, they can then communicate this to senior leadership allowing for real-time evaluation of the culture change effort and giving leadership the leverage to seek out 'bolder' change strategies that complement the demonstrated success of the original change. All this, without sacrificing the benefits of sustainable improvement.

Proposition 3a: The greater the 'tension' between exploration and exploitation at different levels of an organization, the more successful the organization will likely be in implementing patient safety culture change

\section{Relating exploration and exploitation to antecedents of middle management's influence}

Our propositions reinforce the idea that exploration/ exploitation can clarify the context in which middle management functions most effectively. That is, when middle managers understand their strategic role in the organization, ambiguity and confusion regarding their role would likely be significantly reduced. As well, this framework lends itself well to the typology of middle management laid out by Floyd \& Wooldridge [68], whereby the ambidextrous focus can explain what types of communications will take place both upstream and downstream, and how effective they will be in facilitating strategy implementation.

\section{Limitations and avenues for future research}

The primary limitation of our work is that it presents a model largely based outside of the healthcare literature, and as such its applicability is not assured. However, our review of the literature demonstrating factors associated with PSC change support the theoretical effectiveness of this model, particularly the important role of leadership at multiple organizational levels. As well, certain studies have emphasized the unique position of the middle manager in communicating vision and 'trickling down' organizational change goals. This evidence supports the exploration/exploitation framework in predicting middle managers' most effective behaviours in influencing innovation implementation, and in particular the innovation of PSC.

Regarding the role of the exploration/exploitation model of middle management, to be sure this model cannot account for all antecedents of middle management's effectiveness, notably when considering individual antecedents. Nevertheless, the model does frame the variety of contextual factors in a meaningful way to better understand how middle managers will be able to successfully implement organizational change.

Finally, this theoretical framework draws on a number of assumptions that need to be tested empirically, not the least of which includes that healthcare organizations have in fact adopted a primarily exploration-based focus. This should be addressed in future research, as well as the assumption of the present model that middle managers will be most effective when they adopt an ambidextrous focus. Future research in this area may not only involve defining which lens is optimal for each level of the organization, but also looking at how the interconnections and the aforementioned tensions at all three levels work together, perhaps as a necessary antecedent to change

\section{Conclusion}

This paper presents a new model to understand the influential role of middle management in influencing organizational change, specifically in the context of patient safety culture. The extant literature on leadership at the mid-level of organizations, both within and beyond healthcare was used to frame a series of propositions for middle management's contribution to radical organizational change. Through this, we suggest a new framework based on organizational learning theory and the exploration vs. exploitation paradigm; this framework suggests that, through an ambidextrous approach 
to organizational change strategy, middle managers can leverage their unique position in the organization to most effectively influence patient safety change. This organizational learning perspective offers a novel way of framing the mid-level managers' role, through both explorative and exploitative activities, that contributes to our knowledge of the role of middle managers in organizational change.

\section{Abbreviations}

KM: Knowledge Management; PSC: Patient Safety Culture

\section{Acknowledgments}

Not applicable.

\section{Funding}

Not applicable.

\section{Availability of data and materials}

Not applicable.

\section{Authors' contributions}

$J G$ developed the initial draft of the manuscript, based on conceptual discussions with $W B$, who offered expertise in the field of organizational learning. Both authors contributed meaningfully to subsequent drafts and revisions of the manuscript. Both authors read and approved the final manuscript.

\section{Ethics approval and consent to participate}

Not applicable.

\section{Consent for publication}

Not applicable.

\section{Competing interests}

WB is a member of the editorial board (Associate Editor) of this journal.

\section{Publisher's Note}

Springer Nature remains neutral with regard to jurisdictional claims in published maps and institutional affiliations.

\section{Received: 23 January 2017 Accepted: 11 August 2017}

Published online: 22 August 2017

\section{References}

1. McKnight LL. Transformational leadership in the context of punctuated change. J Leadersh, Account and Ethics. 2013;10(2):103-12.

2. Nadler DA, Tushman ML. Beyond the charismatic leader: leadership and organizational change. Calif Manag Rev. 1990;32(2):77-97.

3. Reed P, Conrad D, Hernandez S, Watts C, Marcus-Smith M. Innovation in patient-centered care: lessons from a qualitative study of innovative health care organizations in Washington state. BMC Fam Pract. 2012;13(1):120.

4. Beckett P, Field J, Molloy L, Yu N, Holmes D, Pile E. Practice what you preach: developing person-centred culture in inpatient mental health settings through strengths-based, transformational leadership. Issues in mental health nursing. 2013;34(8):595-601.

5. Miake-Lye IM, Hempel S, Ganz DA, Shekelle PG. Inpatient Fall Prevention Programs as a Patient Safety StrategyA Systematic Review. Annals of Internal Medicine. 2013;158(5_Part_2):390-6.

6. Thomas L, Galla C. Republished: building a culture of safety through team training and engagement. Postgrad Med J. 2013;89(1053):394-401.

7. Peterson $\mathrm{TH}$, Teman SF, Connors RH. A safety culture transformation: its effects at a children's hospital. J Patient Saf. 2012;8(3):125-30.

8. Grabowski DC, Elliot A, Leitzell B, Cohen LW, Zimmerman S. Who are the innovators? Nursing homes implementing culture change. The Gerontologist. 2014;54(Suppl 1):S65-75.
9. Moffatt-Bruce S, McAlearney AS, Aldrich A, Latimer T, Funai E. Engaging the health care team through operations councils: strategies to improve population health from within. Adv in Health Care Manage. 2014:16:51-67.

10. Cohen MM, Eustis MA, Gribbins RE. Changing the culture of patient safety: Leadership's role in health care quality improvement. Jt Comm J Qual Patient Saf. 2003;29(7):329-35.

11. Chreim S, Williams BE, Coller KE. Radical change in healthcare organization: mapping transition between templates, enabling factors, and implementation processes. J Health Organ Manag. 2012;26(2):215-36.

12. Floyd SW, Wooldridge B. Middle management's strategic influence and organizational performance. J Manag Stud. 1997;34(3):465-85.

13. Wooldridge B, Schmid T, Floyd SW. The middle management perspective on strategy process: contributions, synthesis, and future research. J Manag. 2008:34(6):1190-221.

14. Willis CD, Saul J, Bevan H, Scheirer MA, Best A, Greenhalgh T, et al. Sustaining organizational culture change in health systems. J Health Organ Manag. 2016;30(1):2-30.

15. Balogun J. From blaming the middle to harnessing its potential: creating change intermediaries. Br J Manag. 2003;14(1):69-83.

16. Pappas JM, Wooldridge B. Middle Managers' divergent strategic activity: an investigation of multiple measures of network centrality. J Manag Stud. 2007:44(3):323-41.

17. Tabrizi B. The key to change is middle management. Harv Bus Rev. 2014

18. Wachter RM. Patient safety at ten: unmistakable progress, troubling gaps. Health Aff. 2010;29(1):165-73.

19. Harvey G, Jas P, Walshe K, Skelcher C. Analysing organisational context: case studies on the contribution of absorptive capacity theory to understanding inter-organisational variation in performance improvement. BMJ quality \& safety. 2014; bmjqs-2014-002928.

20. Narine L, Persaud DD. Gaining and maintaining commitment to large scale change in healthcare organizations. Health Serv Manag Res. 2003;16(3):179-87.

21. Denis J-L, Langley A, Sergi V. Leadership in the plural. Acad Manag Ann. 2012;6(1):211-83.

22. Skela Savič B, Robida A. Capacity of middle management in health-care organizations for working with people-the case of Slovenian hospitals. Hum Resour for Health. 2013:11:18.

23. Currie G. Reluctant but resourceful middle managers: the case of nurses in the NHS. J Nurs Manag. 2006;14(1):5-12.

24. Eicher JP. Making strategy happen. Perform Improv. 2006;45(10):31-7,48.

25. Benn J, Burnett S, Parand A, Pinto A, Iskander S, Vincent C. Studying largescale programmes to improve patient safety in whole care systems: challenges for research. Social science \& medicine (1982). 2009:69(12):1767-76.

26. March JG. Exploration and exploitation in organizational learning. Organ Sci. 1991:2(1):71-87.

27. Jansen JJP, Van Den Bosch FAJ, Volberda HW. Exploratory innovation, exploitative innovation, and performance: effects of organizational antecedents and environmental moderators. Manag Sci. 2006;52(11):1661-74.

28. Li Y, Zhou N, Si Y. Exploratory innovation, exploitative innovation, and performance: influence of business strategies and environment. Nankai Bus Rev Int. 2010;1(3):297-316.

29. Benner MJ, Tushman ML. Exploitation, exploration, and process management: the productivity dilemma revisited. Acad Manag Rev. 2003;28(2):238-56.

30. Corrigan JM. Crossing the quality chasm. Build a Better Deliv Syst. 2005.

31. Kohn LT, Corrigan JM, Donaldson MS. To err is human:: building a Safer Health System: National Academies Press; 2000.

32. Grant M. IS PATIENT SAFETY IMPROVING? Can J Med Lab Sci. 2011;73(2):23-6.

33. Baker GR, Norton PG, Flintoft V, Blais R, Brown A, Cox J, et al. The Canadian adverse events study: the incidence of adverse events among hospital patients in Canada. Can Med Assoc J. 2004;170(11):1678-86.

34. Committee on Redesigning Health Insurance Performance Measures P, and Performance Improvement Programs. Performance Measurement: Accelerating Improvement. Washington, DC: Institute of Medicine; 2006.

35. Pronovost PJ, Goeschel CA, Marsteller JA, Sexton JB, Pham JC, Berenholtz SM. Framework for patient safety research and improvement. Circulation. 2009;119(2):330-7.

36. Thomas L, Galla C. Building a culture of safety through team training and engagement. BMJ Quality Safety. 2012;22(5):425-434. 
37. Leape LL, Berwick DM. Five years after to err is human: what have we learned? JAMA. 2005;293(19):2384-90.

38. Clancy C. Patient Safety: One Decade after To Err Is Human. Patient Safety \& Quality Healthcare. 2009;September/October 2009.

39. Cameron KS, Quinn RE. Diagnosing and changing organizational culture: based on the competing values framework. San Francisco, CA: John Wiley \& Sons; 2005.

40. Morello RT, Lowthian JA, Barker AL, McGinnes R, Dunt D, Brand C. Strategies for improving patient safety culture in hospitals: a systematic review. BMJ quality \& safety. 2013;22(1):11-8.

41. Mearns KJ, Flin R. Assessing the state of organizational safety-culture or climate? Curr Psychol. 1999;18(1):5-17.

42. Nolan TW. Execution of strategic improvement initiatives to produce system-level results. IHI innovation series white paper Cambridge. Institute for Healthcare Improvement: MA; 2007.

43. Weaver SJ, Lubomksi LH, Wilson RF, Pfoh ER, Martinez KA, Dy SM. Promoting a culture of safety as a patient safety strategy: a systematic review. Ann Intern Med. 2013;158(5 Pt 2):369-74

44. Weaver SJ, Rosen MA, DiazGranados D, Lazzara EH, Lyons R, Salas E, et al. Does teamwork improve performance in the operating room? A multilevel evaluation. Jt Comm J Qual Patient Saf. 2010;36(3):133-42.

45. Hoffmann B, Müller V, Rochon J, Gondan M, Müller B, Albay Z, et al. Effects of a team-based assessment and intervention on patient safety culture in general practice: an open randomised controlled trial. BMJ Quality \&amp; Safety. 2014;23(1):35-46.

46. Teri McConville ULLI. Devolved HRM responsibilities, middle-managers and role dissonance. Pers Rev. 2006;35(6):637-53.

47. Kreindler SA, Larson BK, Wu FM, Gbemudu JN, Carluzzo KL, Struthers A, et al. The rules of engagement: physician engagement strategies in intergroup contexts. J Health Organ Manag. 2014;28(1):41-61.

48. Applebaum SH, Wohl L. Transformation or change: some prescriptions for health care organizations. Manag Serv Qual. 2000;10(5):279-98.

49. Junior VM, Pascucci L, Murphy JP. Implementing strategies in complex systems: lessons from Brazilian hospitals. Brazilian Adm Rev. 2012;9:19-37.

50. O'Shannassy T. Investigating the role of middle managers in strategymaking process: an Australian mixed method study. J Manage Organ. 2014;20(2):187-205.

51. Woollard M, Lewis D, Brooks S. Strategic change in the ambulance service: barriers and success strategies for the implementation of high-performance management systems. Strateg Chang. 2003;12(3):165.

52. Currie $\mathrm{G}$, Procter $\mathrm{S}$. Exploring the relationship between $\mathrm{HR}$ and middle managers. Hum Resour Manag J. 2001;11(3):53-69.

53. Sorensen R, Paull G, Magann L, Davis J. Managing between the agendas: implementing health care reform policy in an acute care hospital. J Health Organ Manag. 2013;27(6):698-713.

54. Thomas AM. Strategic planning: a practical approach. Nurs Manag. 1993;24(2):34.

55. Chaston I. Assessing strategic behaviour within the acute sector of the National Health Service. J Manag Med. 1994;8(5):58.

56. Dainty KN, Sinclair D. A critical qualitative study of the position of middle managers in health care quality improvement. J Nurs Care Qual. 2017;32(2):172-9.

57. Dannapfel P, Poksinska B, Thomas K. Dissemination strategy for lean thinking in health care. Int J Health Care Qual Assur. 2014;27(5):391-404.

58. Fleiszer AR, Semenic SE, Ritchie JA, Richer M-C, Jean-Louis D. An organizational perspective on the long-term sustainability of a nursing best practice guidelines program: a case study. BMC Health Serv Res. 2015;15

59. Corbridge C. Pandora's box: clinical directorates and the NHS. J Manag Med. 1995;9(6):16.

60. Van der Wees PJ, Friedberg MW, Guzman EA, Ayanian JZ, Rodriguez HP. Comparing the implementation of team approaches for improving diabetes care in community health centers. BMC Health Serv Res. 2014;14

61. Shanley C. Managing change through management development: an industry case study. J Manag Dev. 2007;26(10):962-79.

62. Engle RL, Lopez ER, Gormley KE, Chan JA, Charns MP, Lukas CV. What roles do middle managers play in implementation of innovative practices? Health Care Manag Rev. 2017;42(1):14-27.

63. Birken $\mathrm{S}$, Lee $\mathrm{S}-\mathrm{Y}$, Weiner $\mathrm{B}$. Uncovering middle managers' role in healthcare innovation implementation. Implement Sci. 2012;7(1):28.
64. Waring J, Currie G, Crompton A, Bishop S. An exploratory study of knowledge brokering in hospital settings: facilitating knowledge sharing and learning for patient safety? Soc Sci Med. 2013;98:79-86.

65. Birken SA, DiMartino LD, Kirk MA, Lee S-YD, McClelland M, Albert NM. Elaborating on theory with middle managers' experience implementing healthcare innovations in practice. Implement Sci 2016;11(1):1-5.

66. Dopson S, Stewart R. What is happening to middle management? Br J Manag. 1990;1(1):3-16

67. Uyterhoeven H. General managers in the middle. Harv Bus Rev. 1989;67(5):136-45.

68. Floyd SW, Wooldridge B. Managing strategic consensus: the foundation of effective implementation. Executive. 1992;6(4):27-39.

69. Kotter JP. Leading change: Harvard business press; 1996.

70. Appelbaum SH, Habashy S, Malo J-L, Shafiq H. Back to the future: revisiting Kotter's 1996 change model. J Manage Dev. 2012;31(8):764-82.

71. Cruikshank RA, Auster ER, Basir NO, Ruebottom T. Middle managers' knowledge of strategy: antecedents, cognitive accuracy and self-awareness. Int J Strateg Change Manage. 2015;6(1):73-99.

72. Currie G, Procter SJ. The antecedents of middle managers' strategic contribution: the case of a professional bureaucracy. J Manag Stud. 2005:42(7):1325-56.

73. Floyd SW, Wooldridge B. Dinosaurs or dynamos? Recognizing middle management's strategic role. Acad Manag Exec. 1994;8(4):47-57.

74. Floyd SW, Wooldridge B. Middle management involvement in strategy and its association with strategic type: a research note. Strateg Manag J. 1992;13(S1):153-67.

75. Lin N. Social capital: a theory of social structure and action: Cambridge university press; 2002.

76. Lin N. Building a network theory of social capital. Connect. 1999;22(1):28-51.

77. Adler PS, Kwon S-W. Social capital: prospects for a new concept. Acad Manag Rev. 2002;27(1):17-40.

78. Andrews R. Organizational social capital, structure and performance. Human Relations. 2010

79. Ahearne M, Lam SK, Kraus F. Performance impact of middle managers' adaptive strategy implementation: the role of social capital. Strateg Manag J. 2014:35(1):68-87.

80. Levin DZ, Cross R. The strength of weak ties you can trust: the mediating role of Trust in Effective Knowledge Transfer. Manag Sci. 2004;50(11):1477-90

81. Argote L, Miron-Spektor E. Organizational learning: from experience to knowledge. Organ Sci. 2011;22(5):1123-37.

82. Argote L. Organizational learning: creating, retaining and transferring knowledge: Springer Science \& Business Media; 2012

83. Nonaka I. A dynamic theory of organizational knowledge creation. Organ Sci. 1994;5(1):14-37.

84. Berta W, Teare GF, Gilbart E, Ginsburg LS, Lemieux-Charles L, Davis D, et al. Spanning the know-do gap: understanding knowledge application and capacity in long-term care homes. Soc Sci Med. 2010;70(9):1326-34.

85. Brown JS, Duguid P. Organizational learning and communities-of-practice: toward a unified view of working, learning, and innovation. Organ Sci. 1991;2(1):40-57.

86. Fiol CM, Lyles MA. Organizational learning. Acad Manag Rev. 1985;10(4):803-13.

87. Nutley SM, Davies HT. Developing organizational learning in the NHS. Med Educ. 2001:35(1):35-42

88. Duncan R. Organizational learning: implications for organizational design. Res Organ Behav. 1979;1:75-123.

89. Simon HA. Bounded rationality and organizational learning. Organ Sci. 1991;2(1):125-34.

90. Berta WB, Baker R. Factors that impact the transfer and retention of best practices for reducing error in hospitals. Health Care Manag Rev. 2004;29(2):90-7.

91. Crossan MM, Lane HW, White RE. An organizational learning framework: from intuition to institution. Acad Manag Rev. 1999;24(3):522-37.

92. Virani $T$, Lemieux-Charles L, Davis DA, Berta W. Sustaining change: once evidence-based practices are transferred, what then? Healthcare Quarterly. 2009;12(1).

93. Huber GP. Organizational learning: the contributing processes and the literatures. Organ Sci. 1991;2(1):88-115.

94. Cyert RM, James G. March. 1963. A behavioral theory of the firm. Englewood Cliffs, NJ: Prentice-Hall; 1992. 
95. Pisano GP, Bohmer RM, Edmondson AC. Organizational differences in rates of learning: evidence from the adoption of minimally invasive cardiac surgery. Manag Sci. 2001;47(6):752-68.

96. Dutton JM, Thomas A. Treating progress functions as a managerial opportunity. Acad Manag Rev. 1984;9(2):235-47.

97. Argyris C, Schön DA. Organizational learning: a theory of action perspective. MA: Addison-Wesley reading; 1978

98. Foster M, Burridge L, Donald M, Zhang J, Jackson C. The work of local healthcare innovation: a qualitative study of GP-led integrated diabetes care in primary health care. BMC Health Serv Res. 2016;16(1):1.

99. Auerbach AD, Landefeld CS, Shojania KG. The tension between needing to improve care and knowing how to do it. N Engl J Med. 2007;357(6):608-13.

100. Pandey S, Sharma R. Organizational factors for exploration and exploitation. J Technol Manag Innov. 2009;4(1):48-58.

101. Gupta AK, Smith KG, Shalley CE. The interplay between exploration and exploitation. Acad Manag J. 2006;49(4):693-706.

102. Raisch S, Birkinshaw J, Probst G, Tushman ML. Organizational ambidexterity: balancing exploitation and exploration for sustained performance. Organ Sci. 2009;20(4):685-95.

103. Benner M, Tushman M. Reflections on the 2013 Decade Award:" Exploitation, Exploration, and Process Management: The Productivity Dilemma Revisited" ten years later. Academy of Management Review. 2015:amr. 2015.0042

104. Posen HE, Levinthal DA. Chasing a moving target: exploitation and exploration in dynamic environments. Manag Sci. 2012;58(3):587-601.

105. Bégin HM, Eggertson L, Macdonald N. A country of perpetual pilot projects. CMAJ : Canadian Medical Association Journal. 2009;180(12):1185.

106. Alexander JA, Hearld LR. What can we learn from quality improvement research? A critical review of research methods. Medical care research and review : MCRR. 2009;66(3):235-71.

107. Hovlid E, Bukve O, Haug K, Aslaksen A, von Plessen C. Sustainability of healthcare improvement: what can we learn from learning theory? BMC Health Serv Res. 2012:12(1):235.

108. Jeffcott S. The spread and sustainability of quality improvement in health care. Scotland: 2014

109. Dick EZ, Ford BD. Quality improvement in hospitals: barriers and facilitators. Int J Health Care Qual Assur. 2017:30(1):16-24.

110. Bastian H, Glasziou P, Chalmers I. Seventy-five trials and eleven systematic reviews a day: how will we ever keep up? PLoS Med. 2010;7(9):e1000326.

\section{Submit your next manuscript to BioMed Central and we will help you at every step:}

- We accept pre-submission inquiries

- Our selector tool helps you to find the most relevant journal

- We provide round the clock customer support

- Convenient online submission

- Thorough peer review

- Inclusion in PubMed and all major indexing services

- Maximum visibility for your research

Submit your manuscript at www.biomedcentral.com/submit 